\title{
맘 eResearch
}

eResearch: the open access repository of the research output of Queen Margaret University, Edinburgh

This is an author-formatted version of an article published as:

Reino, Sofia and Frew, Andrew and Albacete-Saez, Carlos (2010) ICT Adoption and Development: Issues in Rural Accommodation. Journal of Hospitality and Tourism Technology Information , 2 (1). (In Press)

\section{Accessed from:}

http://eresearch.qmu.ac.uk/1765/

\section{Repository Use Policy}

The full-text may be used and/or reproduced, and given to third parties for personal research or study, educational or not-for-profit purposes providing that:

- The full-text is not changed in any way

- A full bibliographic reference is made

- A hyperlink is given to the original metadata page in eResearch

eResearch policies on access and re-use can be viewed on our Policies page:

http://eresearch.qmu.ac.uk/policies.html

\section{Copyright $(\subset$ and Moral Rights for this article are retained} by the individual authors and/or other copyright owners.

http://eresearch.qmu.ac.uk 


\title{
ICT Adoption and Development: Issues in Rural Accommodation
}

\author{
Sof?a Reino ${ }^{\mathrm{a}}$ \\ Andrew J. Frewa, and \\ Carlos Albacete-Sáez \\ a Queen Margaret University, UK \\ \{sreinopardinas, afrew\}@qmu.ac.uk \\ b Universidad de Granada, Spain \\ calbacet@ugr.es
}

\begin{abstract}
Purpose - The work described in this paper is of direct relevance to those with an interest in the phenomena surrounding ICT (Information and Communication Technologies) adoption by the rural accommodation sector. The paper provides the results from a preliminary study, which examined differences in the level of inter-firm technology adoption between rural and urban accommodation establishments within a major tourism destination, Scotland. Design/methodology/approach - A survey was conducted, and the results set out here suggested that these differences are only presented with two types of technology, i.e. systems requiring networking infrastructure, and sector-specific applications.

Findings - The discussion suggests that the Neoclassical theory of growth and theory of development from below are contradictory but they complementarily explain different levels of adoption between rural and urban setting.

Research Limitations/Implications - Not only theoretical, but also industry implications and suggestions for further research are presented.

Originality/Value - Previous studies examining these phenomena within other industries suggested that rural businesses tend to have weaker technology adoption than those located in urban settings. However, they fail to provide any conclusive theoretical explanation for these differences.
\end{abstract}

Keywords: ICT adoption, digital divide, rural businesses, growth and innovation, accommodation sector, tourism. Paper type Research paper.

\section{Introduction}

ICT have revolutionised the entire tourism industry (Buhalis and Law, 2008), supporting the development of new business models, by building the bridge between different stakeholders. These new technologies have been extensively adopted by airlines, hotel chains, travel agencies, tourism management organisations, etc. (Karanasios and Burgess, 2008). Marketing and distribution have been the business areas reflecting the highest levels of transformation (Buhalis and Law, 2008; Huang, 2008). This is due to the role of technology in supporting the disintermediated marketing and distribution of tourism products.

Some of the benefits that ICT provide to tourism businesses include: more efficient transactions, a low cost distribution chain, improved customer service through personalised services, enhanced service quality and cost reduction (Huang, 2008; Zelenka, 2009). Furthermore, the distribution model of the tourism industry has specific characteristics which make it especially vulnerable to the influence of communication patterns. This is due to its perishable condition and the physical distance between providers and consumers, which make the marketing and distribution especially reliable on an efficient communication process. ICT has shortened distribution channels, making the communication easier and cheaper. Hence, the enormous influence that ICT has presented in the distribution of traditional types of tourism, such as sun and sea, urban and cultural tourism.

Overall, the literature suggests consensus among researchers on the strong development that rural tourism has presented in recent years. This type of tourism has benefited from very substantial support from public institutions. The support received responds to the contribution of this activity to the socioeconomic development of rural settings, which is considered to enhance the quality of life of the host community (Cánoves, Villarino, Priestley and Blanco, 2004; Reichel Lowengart and Milman, 2000). On the other hand, new lifestyles in urban areas are characterised by 
long working hours, high levels of stress and pollution and the scarcity of green areas. These life styles have generated a high demand for natural and traditional landscapes, avoiding the bustle of the city (Lane, 1994).

In relation to the role of rural tourism as an economic activity, the literature suggests that its expansion has continuously taken place not only in developed but also in less developed countries. To illustrate, there are many examples in the literature regarding its development in Spain (Albacete-Sáez, Fuentes-Fuentes and LlorénsMontes2007), Scotland (Frochot, 2005), Taiwan (Huang, 2008), South Africa (Bourgouin, 2002), France, Ireland (Cawley, Marsat and Gillmor, 2007), Canada (Koster and Lemelin, 2009), Malasia (Liu, 2006), Israel (Reichel et al., 2000), etc. Additionally, accommodation constitutes one of the key business activities covering the living expenses of a significant number of families in many rural settings (Albaladejo-Pina and Díaz-Delfa, 2009). Many of the areas failing to sustain the competitiveness of the agriculture have seen their income complemented by tourism, and especially, by accommodation activities.

There are multiple definitions of the concept rural tourism. These respond to the diversified typology of accommodation establishments which can be found in rural settings. Their nature can relate to a historical background, a new commercial development or a family house. Additionally, the nomenclature also varies across geographical locations. To reflect this, Valdés (1996) suggests that there are different denominations for similar establishments, and similar denominations for different establishments. Thus, in this type of locations we can find bed and breakfasts, rural houses, rural hotels, hostels, cottage, zimmer frei, gîtes, etc. Nevertheless, and regardless of the denomination, which might be given by commercial, cultural or regulatory reasons, here rural establishments refer to those businesses providing lodging for tourists. This definition includes all the accommodation establishments, regardless of the number of individuals they lodge, or the provision of food service.

Among the most common characteristics of these establishments, the literature suggests that they tend to be small businesses, indeed micro-enterprises, both physically, and in relation to their scope (Cawley and Gillmor, 2008), they tend to lack resources, are normally related to family businesses (Albaladejo-Pina and DíazDelfa, 2009) and by their definition, they tend to be located far away from urban areas. The Organisation for Economic Co-operation and Development (OECD) especially acknowledges the strategic role of ICT in rural settings to bypass the challenges of communication presented by their physical distance (OECD, 2001). However, the business research literature suggests that those establishments located in rural settings tend to present lower levels of ICT adoption (de Noronha Vaz, Morgan and Nijkamp, 2006). Therefore, based on this evidence it would seem obvious to assume that these differences will also be encountered in the tourism industry. Nevertheless, to the knowledge of the researchers, no previous work has proven this empirically and analysed the reasons underpinning these differences.

This article presents the results from an exploratory study, which is part of a major project measuring the influence of a wide range of variables on ICT adoption. It builds upon communications theory, i.e. diffusion of innovations by Rogers (1969), aiming to examine patterns of ICT adoption by rural accommodation establishments. The phenomenon is then examined from the perspective of two major economic theories, neoclassic economic theory and development from below. The underlying nature of the ICT adoption differences presented by rural and urban establishments translates in clear theoretical and practical implications in the final section of the paper.

\section{Literature Review}

Reflecting the overwhelming role that ICT has played in the last three decades in reshaping the communication of our industry and society, technology adoption has been extensively covered in the research literature (Buhalis and Law, 2008). Overall, and despite the benefits of ICT for the communication of businesses located in remote areas, the literature suggests that businesses tend to present lower levels of ICT adoption (de Noronha Vaz et al., 2006).

In tourism, previous studies have provided an insight into technology adoption by establishments located in rural settings, including a study developed in Scotland (Irvine and Anderson, 2008). However, these did not develop comparisons between the level of adoption between rural and urban establishments. On the other hand, the influence of geographical location on ICT adoption by the accommodation sector has been examined by comparing different regions (Schegg, Murphy and Leuenberger, 2003) but they did not place any focus on the dichotomy rural/urban 
settings.

Furthermore, the literature suggesting different levels of adoption reaches no clear consensus over the underlying reasons. Given this lack of understanding, and the growth of rural tourism, research exploring this phenomenon is needed. Communications and economic theory may be employed to seek to explain these differences.

\section{Technology Adoption and Communications Theory}

Research on ICT adoption, uptake, capability and capacity of use is mainly directed to the development of forecasting studies, and the identification of barriers and drivers of technology adoption (Kauffman \& Kumar, 2005). Two main approaches can be adopted for the study of this phenomenon. These are intra-firm and inter-firm adoption. The former relates to the process by which one technology is fully adopted by a firm from its purchase to the full integration as part of the business strategy. The latter refers to the phenomena by which technology adoption takes place among businesses (Battisti \& Stoneman, 2003), regardless of the level of integration. The authors of this paper acknowledge that technology adoption takes place in stages. This implies different levels of technology adoption can be identified in businesses. However, for the purpose of this paper, which is mainly exploratory, adoption has been measured in terms of inter-firm. Nevertheless, both inter- and intra-firm adoption share some common theoretical assumptions. Most research looking into intra- and inter- adoption (Luengo-Jones, 2001; Scott Morton, 1991; and Thorp, 1998) builds upon communication theory. More specifically, this tends to be based upon the diffusion of innovations theory (Rogers, 1969). This theory refers to a collection of models, developed by Rogers (1969). These explain the process by which innovation, including ICT, is embraced by users.

The adoption of an innovation would be initiated with the identification of a problem which is considered solvable through this adoption, and originated from a small number of centralized legitimizing individuals and then diffused to the other individuals of the system through the available communication channels. According to this theory the four main elements of the process are the social system, the communication channels, the time factor and the characteristics of the innovation.

The social system would relate to a group of individual who are engaged into achieving a specific goal. This will Individuals will be innovators, early adopters, early majority, late majority, and laggards. The communication channel relates to the means by which a message is communicated, which can include heterophily (different) or homophily (similar) individuals. Communication will be better between homophily individuals, however, a certain degree of difference in relation to their knowledge about the innovation will be needed. The time factor will be involved in the innovation-decision process; innovativeness; and innovation's rate of adoption. And finally, the characteristics of the innovation also have an effect on its own adoption. These can be defined according to their its relative advantage, compatibility, complexity, triability and observability of the potential results emerging from its adoption.

Previous studies on ICT adoption by tourism businesses have focused on examining the influence that the characteristics of the social system or organisational structure together with the communication channels have on ICT adoption (e.g. Gretzel, Fesenmaier and O'Leary,2001). Furthermore, extant research has also examined the time factor (Murphy, Schegg and Olaru,2006). On the other hand very little work has focused on understanding the influence that the characteristics of innovations themselves have on their own adoption. This could be due to the assumption underlying most of this research, suggesting that growth, in this case technology adoption, takes place on stages. It follows the suggestions by Nolan (1973) by which growth goes through four different stages, including initiation, contagion, control and integration. On the other hand, presumptions about the influence of characteristics of innovations on their adoption, as suggested by Rogers' (1969), imply that innovations may not finally be adopted. This would enter into conflict with the assumption that adoption of innovations takes place in a prescribed process. The stages approach suggested by Nolan's (1973) implies the eventual adoption of technology.

\section{Economic Theory: ICT and Growth}

Assumptions over the existence of specific patterns of adoption are determined by a specific view on growth and development. Two main theories of growth could provide different rationales about different levels of ICT adoption 
in rural settings. These are the neoclassical economic theory (Greiner, 1972) and the development from below (Sthör, 1981).

The neoclassical economic theory envisions technology adoption as an end on itself. According to this theory, the growth and development of organisations is a form of evolution. This understanding of growth considers spatial manifestation as the growth centre concept (Stöhr, 1981). According to this theory, growth takes place due to external influence and impulse for innovation.

As previously suggested, most research on ICT adoption has been based on these assumptions. Therefore, it has mainly focused on the identification of the stages of adoption (King and Teo, 1997), and of those effects interfering, including a) rank, b) stock-order, and c) epidemic (Bocquet and Brossard, 2007).

a) Rank effects refer to those business characteristics associated with technology adoption. These include organisational factors (Gretzel et al. 2001), sector/supply chain characteristics (Windrum and de Berranger, 2002) and business endogenous characteristics. This latter has been extensively researched in tourism by looking into variables such as size (Hollenstein, 2004; Murphy, Raffa and Mizerski, 2003; Schegg et al., 2003; Siguaw, Enz and Namasivayam, 2000; Windrum and de Berranger, 2002), business age (Schegg et al., 2003; Windrum and de Berranger, 2003), operating status (Gherissi-Labben, Schegg and Murphy, 2002; Hashim, Olaru, Scaglione and Murphy, 2006; Murphy et al., 2006; Schegg et al., 2003; Siguaw et al., 2000; Windrum and de Berranger 2002), and geographical location (Windrum and de Berranger, 2002). It closely aligns with the social system element suggested by Rogers' (1969) diffusion of innovation.

b) The epidemic effects relate to the level of accessibility that businesses have to the sources of innovation. The location, such as the rural/urban divide translates into main epidemic effects. These may act as fundamental barriers for ICT adoption, including the lack of knowledge about ICT in general (Huang, 2008); and its benefits, together with the limited infrastructure (Bourgouin, 2002). It clearly reflects the communication channels element suggested by Rogers' (1969) diffusion of innovation.

c) And finally, the Stock-order effects include two opposed effects which can influence each other. These relate to the marginal gains emerging from ICT adoption and the order effects to the competitive advantage emerging from the adoption of technology. However, this can only be observed through research including a temporal dimension (Battisti and Stoneman, 2003; Bocquet and Brossad, 2007). It is very much in line with the time element suggested by Rogers' (1969) diffusion of innovations.

However, as previously suggested, this assumes a prescribed process of development. As a reaction to this stream of thought, Stöhr (1981) and his followers advocate that the neoclassic theory mistakenly presupposes that there is only one path of growth and development. According to these researchers this theory has policy implications, as it places limitations for innovative paths of development. This stream of thought has lead to what has been known as development from below.

The theorists advocating the development from below consider that evolution takes place by maximising the mobilisation of each area's natural, human, and institutional resources with the primary objective of satisfying the needs of the inhabitants of that area. This implies that the requirements are located-based and may vary across different locations. Hence, policies should be specifically developed for those areas where these will be implemented, as there will be mistrust on those policies which are transferred from other areas. If this is the case, different technological requirements could be arisen at businesses located in different settings. And in the context of this project, it could imply that establishments located in rural settings may have different technological requirements to those located in urban areas.

\section{Problem Identification}

The literature suggested different levels of ICT adoption by businesses located in urban and rural areas but this has not been proven in hospitality and tourism. However the literature review suggested two conflicting theories of growth explaining the existence of potential differences. 
Figure 1. Conceptual Framework

Figure 1 graphically represents the influence that these three theories (theories of growths and the diffusion of innovations) have had on the ICT adoption research. As suggested earlier, extant research has looked at the influence that rank, epidemic and stock-order effects have on ICT adoption. These studies reflect the direct influence that both the neoclassic economic theory and the diffusion of innovations have had on ICT adoption research. However, there is limited work examining the influence that the characteristics of the innovations suggested by Rogers (1969) have on their own adoption - represented with a question mark in Figure 1. Interestingly, this is also the element that suggests a conflict between the diffusion of innovation communication theory and the neoclassic economic theory. On the other hand, this element aligns the development from below economic theory.

Therefore, this paper will examine the phenomena within the context of tourism, in an attempt to answer the following research questions: 1) Do tourism establishments located in rural areas present different levels of ICT adoption to those located in urban areas? If this is the case 2) can these differences be explained through the diffusion of innovations theory? And finally 3 ) which theory of development is more suitable to explain the pattern described by this adoption?

\section{Methods}

In an attempt to examine these research questions, an electronic survey was developed through the Scottish accommodation sector. This was mainly composed of two central sets of data, namely the availability of systems and the characteristics of the establishments, including their area of location. Finally, comment boxes were placed throughout the questionnaire, and demographic data about the participants was collected, controlling for the effect of potential sources of error.

The information about the availability of systems was collected through closed-ended questions. This was due to the type of information which was being collected, binary data on the availability of system (Yes or No). This list of systems emerged from the eTourism literature (Buhalis, 2003; Murphy et al., 2003; O'Connor, 2004; Schegg et al., 2003) and included Front-Office, Business Administration, Yield Management, Business Intelligence, Guest Service, Hardware and General Networking Infrastructure. A glossary explaining the terminology was provided to support participation.

Closed-ended questions also collected the information regarding the characteristics of businesses. These included the Geographical Location, Business Type, Size, Age of Establishments, Operating Status, Type of Ownership and Market Segmentation. The selection responds to the findings from the literature review (Gherissi-Labben et al., 2002; Hashim et al., 2006; Hollenstein, 2004; Murphy et al., 2003; Murphy et al., 2006; Schegg et al., 2003; Siguaw et al., 2000; Windrum and de Berranger, 2002). These characteristics were self-defined, and the data emerging from these questions was binary or categorical, depending on the number of typologies defining the specific business characteristics. 
The most accurate record of the accommodation sector is that one held by VisitScotland (Public body, responsible for the Scottish tourism marketing). The electronic questionnaire was piloted prior to its distribution. The accommodation sector database held by VisitScotland, comprised 7,671 establishments including 898 hotels, 872 guest houses, 1,917 bed and breakfast, 3,783 non-serviced accommodation and 201 hostels. Some of these businesses (743) did not have an email address in their record and these were omitted from the sampled population. This presented sampling implications. However, it was expected that businesses without an email address could not be expected to have adopted a significant number of ICT. On the other hand, only twenty three emails 'bounced' during the distribution of the questionnaire demonstrating the accuracy of the database.

The response rate $(6.9 \%)$ while not particularly high in absolute terms, produced a high volume of valid responses (477) since the entire (accommodation provider) population was invited to participate in the study. Furthermore, it includes representation of businesses located both in rural and urban areas (320 and 157 respectively). Additionally, the sample error for an infinite population was of about $4.49 \%$ for a confidence level of $95.5 \%(p=q=0.5)$ which previous studies have suggested as acceptable (Baker and Crompton, 2000; Lam and Zhang, 1999; Reichel et al., 2000). Additionally, it presented a successful representation of the different business type, star rating and size categories.

The data, binary and categorical, did not fulfil the requirements for the application of parametric techniques. Therefore non-parametric techniques were selected for the analysis. The use of a multivariate analysis which supports the exploration of patterns in categorical data, i.e. cluster analysis, was considered. However, the shape of the dataset, composed of a large number of systems with wide variation of results did not support the extraction of clear multivariate patterns. Nevertheless, the reliability of this technique is limited (Hair, Black, Babin, Anderson, and Tathan (2006)) and therefore, bivariate techniques were selected to support the examination of potential patterns of adoption presented by the individual systems. The influence of each business characteristic on the uptake of individual systems was examined. The results supported theory development in terms of the patterns of adoption presented by business categories, and decisions related to the generation of composite indicators. The selected bivariate techniques consisted of Spearman's rho correlation for numerical business characteristics, and Chi-Square Significance Tests for the categorical ones. When the assumptions for the Chi-Square test related to the minimum expected cell count were not met, the results were corroborated through the Fisher Exact Test, which is assumptions-free.

\section{Findings}

The analysis through contingency tables revealed different levels of technology adoption between those businesses located in urban and rural locations. These differences are summarised in Figure 2. Similarly to those findings presented by previous research on other business domains (OECD, 2001), these results indicated that overall, the level of technology adoption is lower at those accommodation establishments which are located in rural settings than those in urban areas. 


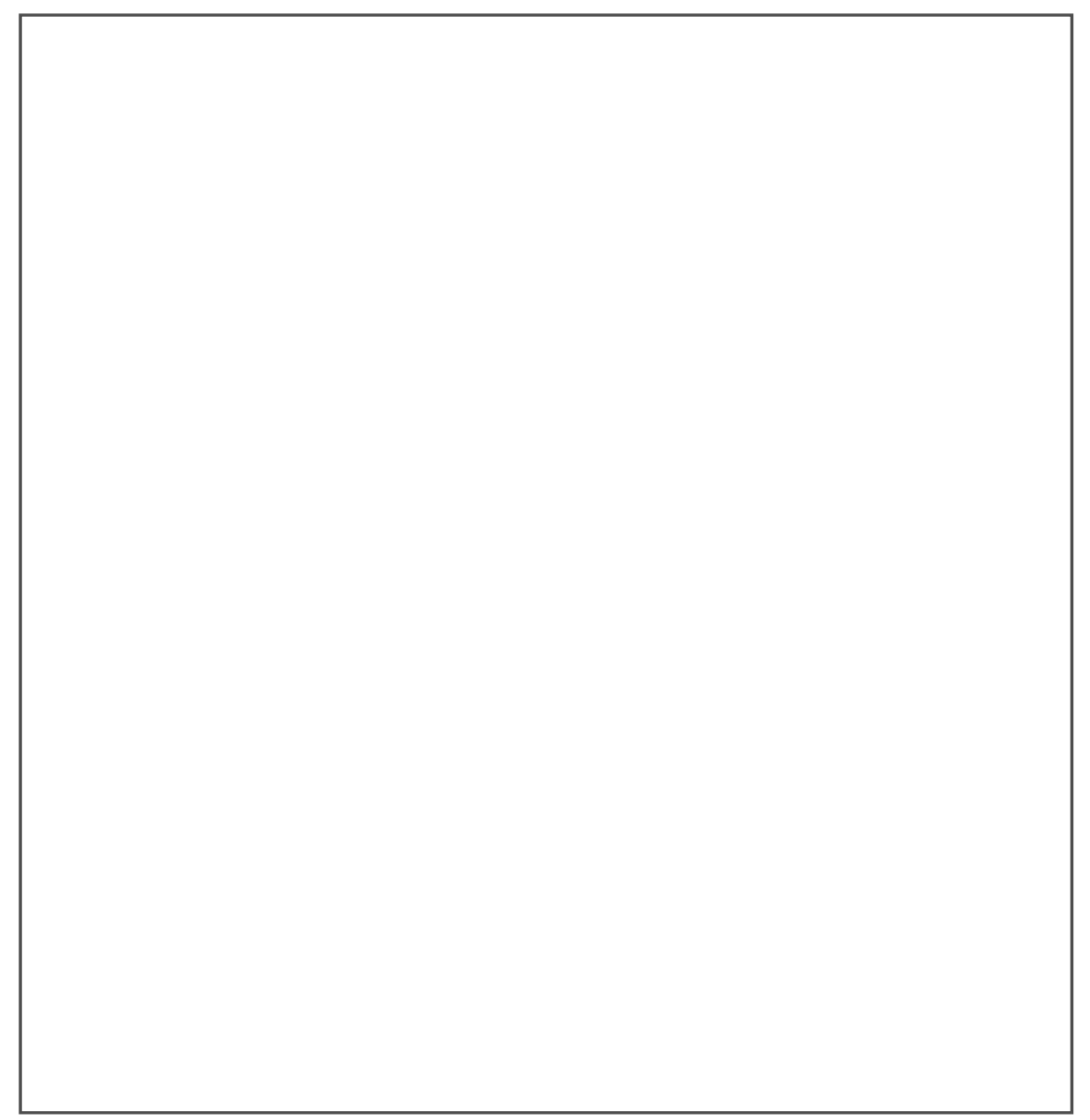

Figure 2. Comparison of ICT Uptake by Rural and Urban Accommodation in Scotland

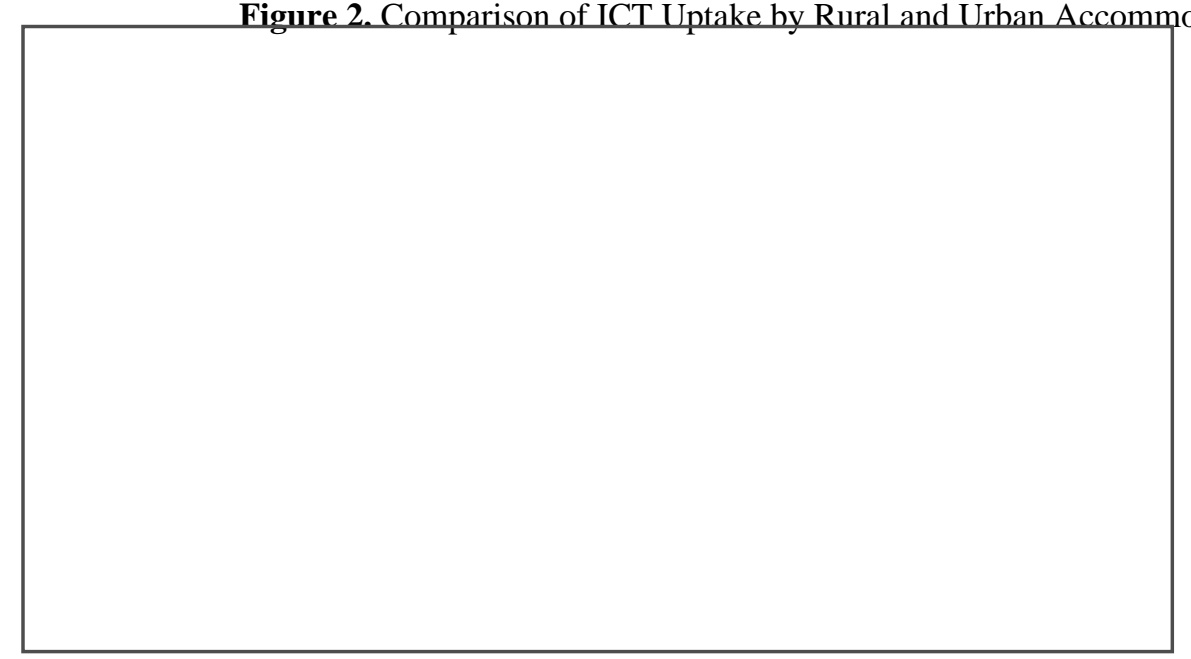




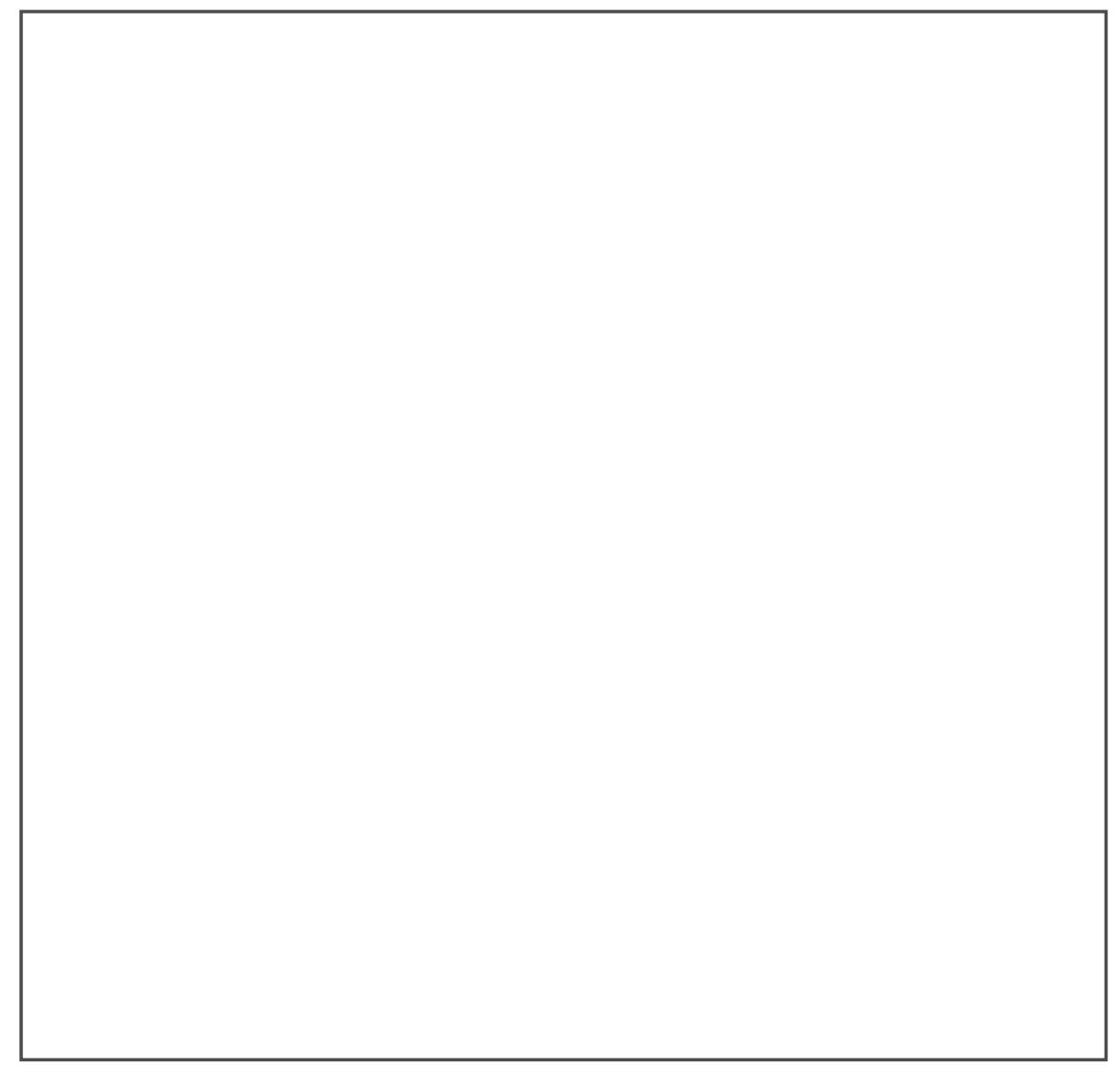

Figure 3. Systems with Influence of Area of Location on Uptake

However, the results from the Chi-Square Test suggested that this influence is only statistically significant $(\mathrm{p}<0.05)$ in a limited number of systems. These results are presented in Figure 3. As it can be observed, these only include systems requiring networking infrastructure (Remote Access to Company Network, Company Website, Intranet, Payas-you-go In-Room Internet and Free In-Room Internet) as well as applications which are sector-specific(Property Management Systems, Global Distribution Systems and Alternative Distribution Systems).

Table 1. ICT Systems without Influence of Area of Location on Uptake

\begin{tabular}{|c|c|}
\hline Accounts Receivable $(n=89)$ & $\begin{array}{l}\text { In-Room Sensor Motion } \\
(n=6)\end{array}$ \\
\hline Company Website $(n=276)$ & In-Room Telephone $(n=74)$ \\
\hline Customer Relationship & In-Room Thermostat \\
\hline Management $(n=48)$ & $(n=199)$ \\
\hline $\begin{array}{l}\text { Destination Marketing Systems } \\
(\mathrm{n}=71)\end{array}$ & Intranet $(\mathrm{n}=42)$ \\
\hline Room Status Annunciation $(n=8)$ & $\begin{array}{l}\text { Key Card Energy Switch } \\
(n=12)\end{array}$ \\
\hline $\begin{array}{l}\text { Energy Management system } \\
(\mathrm{n}=18)\end{array}$ & Laptop $(n=133)$ \\
\hline Electronic-Points-of-Sale & Leisure Management \\
\hline$(n=64)$ & Systems $(n=3)$ \\
\hline General Ledger System ( $n=113)$ & Procurement $(n=16)$ \\
\hline Guest-Operated Heating $(n=293)$ & $\begin{array}{l}\text { Remote Access to Network } \\
(\mathrm{n}=66)\end{array}$ \\
\hline Handheld PC (21) & Sales \& Marketing $(n=67)$ \\
\hline Human Resources system (25) & Self-Service Kiosk $(n=7)$ \\
\hline Electronic Door Locking $(n=11)$ & Voice-Over-IP $(\mathrm{n}=31)$ \\
\hline
\end{tabular}




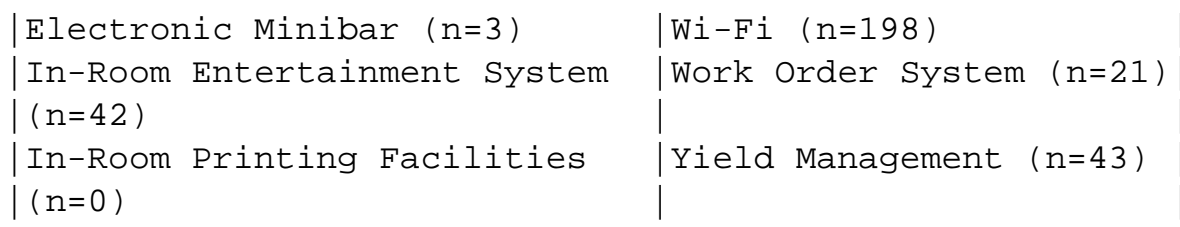

On the other hand, systems whose adoption is not influenced by the location of establishments (Table 1) are mainly of two types. These are 1) applications which are not sector specific (horizontal applications) such as Accounting, Customer Relationship Management, Human Resources Systems, Procurement, Sales \& Marketing, Work Order and Yield Management systems; as well as 2) applications for the use of guests, including Energy Management Systems, Electronic Points of Sale, In-Room facilities and WiFi. Additionally, the majority of these systems do not rely heavily on networking infrastructure. Highlighted in bold, Table 1 presents theonly two exceptions to this rule. These are Voice-Over-IP, which heavily relies on networking infrastructure, and Destination Marketing System, a vertical application. Unlike all the others of their kind the adoption of these two systems is not influenced by the location of the accommodation establishments.

The lack of influence presented by In-Room Printing Facilities cannot be considered a result, due to the lack of adoption of these systems $(n=0)$. However, both Voice-Over-IP and Destination Marketing Systems seem to be exceptions to two rules guiding ICT adoption by accommodation establishments. Overall, the results suggest some interesting patterns of adoption which are determined by the location of accommodation establishments in rural or urban areas. These results align, to some extent, with those suggested by previous research (OECD, 2001, de Noronha Vaz et al., 2006; and Bourgouin, 2002). But this is only partially. Yes, it seems that tourism businesses located in rural areas present different levels of ICT adoption. And it also seems that these differences relate to the lower levels of ICT adoption by rural businesses. These differences could be related to epidemic effects as suggested by this previous literature. And it seems logical that these disparities could be caused by their limited access to resources, as they suggest. However, epidemic effects justify differences across systems, related to the lack of knowledge (Huang, 2008) or different levels of ICT infrastructure adoption (Bourgouin, 2002). Yes, it is true that the results present differences in the level of adoption of most systems requiring networking, and there is only one exception to this rule (Voice-Over-IP). However, epidemic effects do not explain the different levels of adoption of most sector-specific (vertical) applications.

Vertical applications are especially designed to cover the needs of a specific group of businesses. Hence, they count with special characteristics which make them useful to this specific group. Thus, the discriminative influence of rurality on the adoption of vertical applications may imply that the characteristics of these systems might not suit the needs of these establishments. This highlights the important role that innovations have on their own adoption, as suggested by Rogers (1969). Furthermore, it also suggests that the adoption of innovations might not necessarily depend on epidemical factors, but upon the specific needs of the adopting community. This rationale aligns with the views on growth advocated by followers of the theory development from below (Stöhr, 1981).

It should be mentioned that a significant number of additional business characteristics also seemed to influence on the adoption of these and other systems. However, additional multivariate analysis was undertaken in order to test problems of multicollinearity. This analysis enabled the researcher to find out whether the influence of the location in rural areas was genuine or if the influence was actually caused by any other variable. This can be tested by examining the Variance Inflation Factor (VIF) and the Tolerance level. The analysis revealed that the former was always lower than 10 and the latter higher than .100 (Field, 2005), indicating that there was not multicollinearity. Thus, the influence of the location in rural areas on the adoption of these systems is genuine.

\section{Conclusions, Implications and Outlook}

Although the literature review suggested that the phenomenon of ICT adoption by businesses in rural settings had been previously examined, these studies suggested that rural businesses tend to adopt less technology than those located in urban settings. However, research looking more than superficially into the causes underlying this phenomenon has been limited. There are assumptions about limitations regarding epidemic effects in rural areas, 
which reduce their level of ICT adoption. But these assumptions are underlined by a specific view on growth and development. This is clearly the case of the neoclassical economic theory. This theory has been challenged by a different view on growth and development, the development for below. However, apart from theorising, limited studies have explored the reasons lying beneath the different levels of ICT adoption between establishments in rural and urban areas. Furthermore, following the results on other business environments; it seems obvious to expect that different levels of adoption may also take place in the tourism and accommodation sector. The literature commonly agrees on the essential role of ICT supporting the development of tourism, and specifically, accommodation sector (Buhalis and Law, 2008; O'Connor, 2004). However, to the knowledge of the researchers, no studies have actually undertaken this type of comparison within this industry.

This study aims to bring an insight into this topic through an investigation into ICT adoption by Scottish accommodation establishments. A quantitative survey was conducted across the service. The results enabled the examination of patterns describing the ICT adoption by rural and urban establishments.

The results aligned partially with those suggestions from previous research carried out in other businesses. In the accommodation sector, the ICT uptake is also lower in rural than in urban areas. This assumption is now empirically proven through this research. However, this research has also provided a very different outlook to the reasons underlying these differences. These differences can only be observed on the adoption of a few ICT systems which present very specific characteristics. These are mainly sector-specific applications and applications which heavily require a networking infrastructure. The lower levels of adoption of these latter may respond to some epidemic factors. And this is not new. However, the existence of limited epidemic effects may not be able to explain the different levels of ICT systems supporting sector specific activities. With the exception of VisitScotland's Destination Marketing System, all the other sector specific systems presented lower levels of adoption by businesses located in rural areas. This may relate to the unsuitability of these systems in supporting the activities of accommodation establishments which are located in rural areas.

These results suggest that the reasons for the different levels of ICT adoption by rural and urban accommodation establishments could be two-fold. On one hand, epidemic effects seem to influence ICT adoption in rural areas. Those systems which highly rely on networking infrastructure (epidemic effects) tend to present lower levels of adoption. In this sense, ICT adoption can be understood from the perspective outlined by the neoclassical theory of growth. However, the epidemic effects (i.e access to resources) do not explain the different adoption levels presented by vertical applications. In principle, there are no reasons to believe that the adoption of vertical (sector specific) applications may present higher epidemic (e.g. technical or procurement) requirements than horizontal (general business) applications. Thus, there is no reason to believe that the adoption of vertical applications may be influenced by empirical effects to a greater extent than the adoption of horizontal (general business) applications. On the other hand, this suggest that sector-specific applications might not fulfil the requirements of rural accommodation establishments. And this aligns with Sthör's (1981) suggestions of the risks arising from prescribing stages of growth in locations with very diverse backgrounds. Hence, the application of the two major theories of growth for explaining ICT adoption in rural areas may not be contradictory in this case. In turn, these theories of growth may complement each other in providing an explanation to the phenomena of ICT adoption in rural areas.

In addition to the theoretical implications, these findings are also of importance to the industry. On one hand, they suggest limitations related to networking accessibility in some rural areas, at least within Scotland. On the other hand, it implies that rural establishments may have different ICT requirements. This calls for further research and for the development of specific software covering their needs. Furthermore, it raises the question of whether this potential "rural needs" may also apply to other tourism sectors and to the general business population.

While this research is exploratory, it should provide a valuable foundation for further work examining the ICT requirements of rural establishments more widely..

\section{References}

Albacete-Sáez, C. A., Fuentes-Fuentes, M. M., and Lloréns-Montes, F. J. (2007). "Service quality measurement in rural accommodation”. Annals of Tourism Research, Vol. 34, No. 1, pp. 45-65.

Albaladejo-Pina, I. P., and Díaz-Delfa, M. T. (2009). "Tourist preferences for rural house stays: evidence from discrete choice modelling in Spain”. Tourism Management, Vol. 30, No. 6, pp. 805-811. 
Baker, D. A., and Crompton, J. L. (2000). "Quality, satisfaction and behavioral intentions". Annals of Tourism Research, Vol. 27, No. 3, pp. 785-804.

Battisti, G., and Stoneman, P. (2003). "Inter- and intra-firm effects in the diffusion of new process technology". Research Policy, Vol. 32, No. 9, pp. 1641-1655.

Bocquet, R., and Brossad, O. (2007). "The variety of ICT adopters in the intra-firm diffusion process: theoretical arguments and empirical evidence". Structural Change and Economic Dynamics, Vol. 18, No. 4, pp. 409-437.

Bourgouin, F. (2002). "Information communication technologies and the potential for rural tourism SMME development: the case of the Wild Coast". Development Southern Africa, Vol. 19, No. 1, pp. 191-212.

Buhalis, D., and Law, R. (2008). "Progress in information technology and tourism management: 20 years on and 10 years after the Internet - The state of eTourism research". Tourism Management, Vol. 29, No. 4, pp. 609-623.

Buhalis, D. (2003). eTourism. Information technology for strategic tourism management, Pearson Education Limited, Harlow.

Burn, J.M. (1994). A revolutionary staged growth model of information systems planning. Proceedings of the Fifteenth International Conference on Information Systems, Vancouver, British Columbia, Canada, 395-406.

Cánoves, G., Villarino, M., Priestley, G. K., and Blanco, A. (2004). "Rural tourism in Spain: an analysis of recent evolution". Geoforum, Vol. 35, No. 6, pp. 753-767.

Cawley, M., and Gillmor, D. A. (2008). "Integrated rural tourism: concepts and practice”. Annals of Tourism Research, Vol. 35, No. 2, pp. 316-337.

Cawley, M., Marsat, J. -B., and Gillmor, D. (2007). "Promoting integrated rural tourism: comparative perspectives on institutional networking in France and Ireland". Tourism Geographies, Vol. 9, No. 4, pp. 405-420.

De Noronha Vaz, T., Morgan, E.F., and Nijkamp, P. (2006). The new european rurality: strategies for small firms, Ashgate Publishing, Ltd. Aldershot.

Frochot, I. (2005). "A benefit segmentation of tourists in rural areas: a Scottish perspective". Tourism Management, Vol. 26, No. 3, pp. 335-346.

Gherissi-Labben, T., Schegg, R., and Murphy, J. (2002). The state of electronic customer service in the tunisian hotel industry. Proceedings of the $7^{\text {th }}$ Conference of the Association of Information Management (AIM) in Hammamet, Tunisia.

Greiner, L.E. (1972). "Evolution and revolution as organizations grow”. Harvard Business Review, Vol. 50, No. 4, pp. 3746.

Gretzel, U., Fesenmaier, D.F., and O'Leary, J.T. (2001). Assessing the Capacity of Canadian Tourism Organisations to Effectively Use the CTX and other Web-based Technologies. Urbana Champaign, National Laboratory for Tourism and eCommerce, University of Illinois.

Hair, J.F., Black, W.C., Babin, B.J., Anderson, R.E., and Tathan, R.L. (2006). Multivariate Analysis (6 ${ }^{\text {th }}$ ed.). New Jersey: Pearson Prentice Hall.

Hashim, N. H., Olaru, D., Scaglione, M., and Murphy, J. (2006). "A theoretical framework of factors relating to internet adoption stages by Malaysian hotels". In M. Hitz, M. Sigala, and J. Murphy (Eds.). Information and communication technologies in tourism, pp. 196-208. Springer Verlag, Wien-New York.

Hollenstein, H. (2004). "Determinants of the adoption of Information and Communication Technologies (ICT). An empirical analysis based on firm-level data for the Swiss business sector". Structural Change and Economic Dynamics, Vol. 15, No. 3, pp. 315-342.

Huang, L. (2008). "Bed and breakfast industry adopting e-commerce strategies in e-service". The Service Industries Journal, Vol. 28, No. 5, pp. 633-648.

Igbaria, M., Zinatelli, N., and Cavaye, A. (1998). "Analysis of information technology success in small firms in New Zealand". International Journal of Information Management, Vol. 18, No. 2, pp. 103-119.

Irvine, W., and Anderson, A.R. (2008). "ICT (Information communication technology), peripherality and smaller hospitality business in Scotland”. International Journal of Entrepreneurial Behaviour and Research, Vol. 14, No. 4, pp. $200-218$.

Karanasios, S., and Burgess, S. (2008). "Tourism and internet adoption: a developing world perspective". International Journal of Tourism Research, Vol. 10, No. 2, pp. 169-182.

King, W. R., and Teo, T. S. H. (1997). "Integration between business planning and information systems planning: a validating stage hypothesis". Decision Sciences, Vol. 28, No. 2, pp. 279-308.

Koster, R. L. P., and Lemelin, R. H. (2009). "Appreciative inquiry and rural tourism: a case study from Canada". Tourism Geographies, Vol. 11, No. 2, pp. 256-269.

Lam, T., and Zhang, H. Q. (1999). "Service quality of travel agents: the case of travel agents in Hong Kong". Tourism Management, Vol. 20, No. 3, pp. 341-349.

Lane, B. (1994). "What is rural tourism?” Journal of Sustainable Tourism, Vol. 2, No. 1-2, pp.7-21.

Liu, A. (2006). “Tourism in rural areas: Kedah, Malaysia”. Tourism Management, Vol. 27, No. 5, pp. 878-889.

Miles, R. H., and Snow, C. C. (1978). Organizational strategy, structure and process, McGraw-Hill, New York.

Murphy, J., Raffa, L., and Mizerski, R. (2003). "The Use of Domain Names in e-branding by the World's Top Brands". Electronic Markets, Vol. 13, No. 3, pp. 222-232. 
Murphy, J., Schegg, R., and Olaru, D (2006). "Investigating the Evolution of Hotel Internet Adoption”. Information Technology and Tourism, Vol. 8, No. 3, pp. 161-177.

Nolan, R.L. (1973). "Managing the Computer Resource: A Stage Hypothesis". Communications of the ACM, Vol. 16, No 7, pp. 399-405.

O’Connor, P. (2004). Using Computers in Hospitality (3rd ed.), Thomson, Cheshire.

Organization for Economic Co-operation and Development (cited as OECD) (2001), Information and communication technologies and rural development, OECD Publications, París.

Palvia, P., and Palvia, S. (1999). "An examination of the IT satisfaction of small business users". Information and Management, Vol. 35, No. 3, pp. 127-137.

Premkumar, G., and Roberts, M. (1999). "Adoption of new information technologies in rural small businesses". Omega, The International Journal of Management Science, Vol. 27, No. 4, pp. 467-484.

Reichel, A., Lowengart, O., and Milman, A. (2000). "Rural tourism in Israel: service quality and orientation". Tourism Management, Vol. 21, No. 5, pp. 451-459.

Rogers, E. M. (1969). Diffusion of Innovations, The Free Press, New York.

Rosenberg, N. (1982). Inside the Black Box: Technology and Economics, Cambridge University Press, Cambridge.

Schegg, R., Murphy, J., and Leuenberger, R. (2003). "Five-Star Treatment? E-Mail Customer Service By International Luxury Hotels". Information Technology and Tourism, Vol. 6, No. 2, pp. 99-112.

Schegg, R., Scaglione, M., Liebrich, A., and Murphy, J. (2007). Internet Use by Hospitality SMEs in Alpine Destinations. In M. Sigala, L. Mich, and J. Murphy (Eds.). Information and Communication Technologies in Tourism (469-489). Springer Verlag, Wien-New York.

Schegg, R., Steiner, T., Frey, S., and Murphy, J. (2002). "Benchmarking of Web site Design and Marketing by Swiss Hotels". Information Technology and Tourism, Vol. 5, No. 2, pp. 73-89.

Siguaw, J. A., Enz, C. A., and Namasivayam, K. (2000). "Adoption of Information Technology in U.S. Hotels: Strategically Driven Objectives". Journal of Travel Research, Vol. 39, No. 2, pp. 192-201.

Singh, A.J., and Kasavana, M.L. (2005). "The impact of information technology on future management of lodging operations: A Delphi study to predict key technological events in 2007 and 2027". Tourism and Hospitality Research, Vol. 6, No. 1, pp. 24-37.

Stöhr, W.B. (1981). "Development from Below: The Bottom-Up and Periphery-Inward Development Paradigm”. In W.B. Stöhr and D.R.F. Taylor, Development from Above or Below? The Dialectics of Regional Planning in Developing Countries, John Wiley and Sons, Chischester.

Valdés, L. (1996), El turismo rural en España, In Pedreño Muñoz, A., and Monfort Mir, V. M. (ed.): Introducción a la economía del turismo en España, Civitas, Madrid.

Windrum, P., and de Berranger, P. (2002). "The adoption of e-business technology by SMEs", working paper, MERIT and International Institute of Infonomics, Maastricht.

Windrum, P., and de Berranger, P. (2003). "Factors affecting the adoption of intranets and extranets by SMEs: a UK study", working paper, MERIT, Maastricht Economic Research Institute on Innovation and Technology, Maastricht.

Zelenka, J. (2009). "Information and communication technologies in tourism: influence, dynamics, trends". E + M Ekonomie a Management, Vol. 12, No. 1, pp. 123-132.

\section{Acknowledgments}

The authors would like to thank the contribution of VisitScotland and VisitScotland.com in the development of this research. 